\title{
Silibinin inhibits in vitro ketosis by regulating HMGCS2 and NF-kB: elucidation of signaling molecule relationship under ketotic conditions
}

\author{
Dong Young Kang ${ }^{1} \cdot$ Nipin Sp ${ }^{1} \cdot$ Kyung Do Park ${ }^{2} \cdot$ Hak Kyo Lee Ki-Duk Song $^{2,3} \cdot$ Young Mok Yang $^{1}$ iD
}

Received: 16 July 2018 / Accepted: 29 March 2019 / Published online: 25 April 2019 / Editor: Tetsuji Okamoto

(C) The Author(s) 2019

\begin{abstract}
Ketosis is a condition where ketone bodies are produced as an alternative energy source, due to insufficient glucose for energy production so that the body switches from carbohydrate metabolism to mostly fat metabolism. In this study, we examined the anti-ketosis effects of silibinin, a major active component of silymarin. We induced ketosis in FL83B mouse hepatocytes in vitro by culturing in low glucose media and compared results to hepatocytes maintained in high-glucose conditions. We quantified $\beta$ hydroxybutyrate (BHB) levels with a colorimetric assay. In low-glucose conditions, silibinin reduced the amount of BHB produced, compared to high-glucose conditions; thus, silibinin exhibited an anti-ketotic effect. Ketone body formation during beta oxidation is mediated by 3-hydroxy-3-methylglutaryl-CoA synthase 2 (HMGCS2). The nuclear factor kappa-light-chainenhancer of activated B cells (NF-kB) regulates the transcription of HMGCS2, and plays a vital role in BHB levels. We showed that silibinin inhibited the expression of HMGCS2 and NF-kB at transcriptional and translational levels. Silibinin also inhibited the nuclear translocation of NF-kB and its DNA binding activity. To elucidate the relationship between HMGCS2 and NF-kB, we tested inhibited and over-expressed NF-kB. We found that NF-kB acted as a positive regulator for HMGCS2 under ketosis treatment conditions.
\end{abstract}

Keywords HMGCS2 $\cdot$ Ketosis $\cdot \mathrm{NF}-\mathrm{kB} \cdot$ Silibinin

\section{Introduction}

Induction of in vitro ketosis is a convenient method for testing the efficacy of specific drugs designed to treat ketosis and for determining the molecular targets involved. Liver produces ketone bodies (acetoacetate and $\beta$-hydroxybutyrate) from fatty acids in response to fasting, a carbohydrate-restrictive diet, or glucose starvation. The presence of ketone bodies in the

Dong Young Kang and Nipin Sp contributed equally to this work.

Ki-Duk Song

kiduk.song@gmail.com

Young Mok Yang

ymyang@kku.ac.kr

1 Department of Pathology, School of Medicine, Institute of Biomedical Science and Technology, Konkuk University, Chungju 27478, South Korea

2 Department of Animal Biotechnology, Chonbuk National University, Jeonju 54896, South Korea

3 The Animal Molecular Genetics and Breeding Center, Chonbuk National University, Jeonju, South Korea bloodstream could cause a relative imbalance in fat metabolism (Garber et al. 1974). The glucose levels in the body are significantly different in normal conditions and ketotic conditions; low-glucose conditions induce the body to use fat as an alternative energy source; hence, ketosis ensues. Thus, the induction of in vitro ketotic conditions is not difficult; it can be achieved by varying the amount of glucose (D-glucose) in the cell culture medium (Sreekantan Preetha et al. 2015).

Ketosis can be treated with natural substances without side effects. In dairy cows, these substances can be mixed into the feed. Natural products that reduce ketone body concentrations to below $0.5 \mathrm{mM}$ (ketotic conditions), with no adverse effects at the required concentrations, are considered suitable antiketotic drugs. Silibinin is the major active constituent of silymarin, an extract from milk thistle seeds. Silibinin has shown pharmacological effects, due to its structure, which consists of two diastereomers, silybin A, and silybin B (Davis-Searles et al. 2005). Silibinin showed effective pharmacological activity in the liver, when it was used as a supportive element for alcoholic treatments and when it was used to treat child grade "A" liver cirrhosis (Saller et al. 2008). Silibinin is also an anti-cancer drug; it has shown high efficacy 
against various cancers, including colon (Kumar et al. 2014), breast (Wang et al. 2010), bladder (Zeng et al. 2011), skin (Singh and Agarwal 2005), and lung (Mateen et al. 2010) cancers.

Ketosis treatment by targeting molecular pathways is the most efficient treatment. Ketone bodies are produced in mitochondria through beta oxidation (Cotter et al. 2014). The mitochondrial enzyme, 3-hydroxy-3-methylglutaryl-CoA synthase 2 (HMGCS2), converts acetoacetyl-CoA to HMG$\mathrm{CoA}$, which is then converted to ketone bodies, acetoacetate and $\beta$ hydroxybutyrate (BHB). In humans, HMGCS2 is encoded by the HMGCS2 gene. In hepatic mitochondria, mitochondrial HMGCS2 produces HMG-CoA, which is then transformed into acetoacetate by HMG-CoA lyase. Finally, acetoacetate is transformed to hydroxybutyrate and acetone (Hegardt 1999). Ketosis can be controlled at the molecular level by inhibiting the expression of HMGSC2, which reduces beta oxidation. Thus, an anti-ketosis drug that inhibits or down-regulates HMGCS2 activity would reduce ketone body production.

Nuclear factor kappa-light-chain-enhancer of activated B cells (NF-kB) is a transcription factor that regulates the expression of cytokines, chemokines, and adhesion molecules (Lawrence 2009). The NF-kB protein complex controls DNA transcription and cell survival. NF-kB is a rapid-acting, primary transcription factor for c-myc (Duyao et al. 1990), CXCL (Tensen et al. 1999), VCAM (Iademarco et al. 1992), CCL2 (Ueda et al. 1994), etc. It also regulates peroxisome proliferator-activated receptor (PPAR) levels by regulating expression of the $P G C-1 \beta$ gene (Abrahan and Ash 2016). NF$\mathrm{kB}$ is a transcription factor for $\mathrm{HMGCS} 2$; it can regulate the expression of HMGCS2 by regulating PPAR (Vilà-Brau et al. 2011). However, it remains unknown whether NF-kB acts as a positive or negative regulator of HMGCS2 expression. Understanding this relationship can elucidate a molecular pathway that can be targeted in the treatment of ketosis.

In the present study, we investigated the anti-ketotic activity of silibinin. We analyzed its activity on HMGCS2 and NF$\mathrm{kB}$, and we explored the possibility of targeting the HMGCS2/NF-kB pathway in the development of treatments for ketosis. We also elucidated how NF-kB acted on HMGCS2 in ketotic conditions.

\section{Materials and Methods}

Antibodies and reagents Colorimetric assay kit for detecting BHB was purchased from the Cayman Chemical Co. (Ann Arbor, MI). Silibinin and D-glucose were purchased from Sigma-Aldrich (St. Louis, MO). F-12K medium and anti- $\beta$ actin antibody were purchased from Life Technologies (Carlsbad, CA). Penicillin-streptomycin solution and fetal bovine serum (FBS) were purchased from HyClone (South of
Logan, UT). Trypsin-EDTA $(0.05 \%)$ was purchased from Gibco-BRL (Grand Island, NY). Anti-HMGCS2 and antiTBP antibodies were purchased from Abcam (Cambridge, UK). Anti-NF-kB was purchased from Cell Signaling Technology (Danvers, MS). Anti-ANGPTL3 antibody and secondary antibodies (goat anti-mouse and rabbit IgGhorseradish peroxidase) were obtained from Santa Cruz Biotechnology (Santa Cruz, CA). The WesternBright ECL HRP substrate detection solution was purchased from Advansta Inc. (Menlo Park, CA). The NE-PER kit and Restore $^{\mathrm{TM}}$ Western Blot Stripping Buffer were purchased from Pierce (Rockford, IL). QIAprep Spin Miniprep Kit and RNeasy Mini Kit were purchased from Qiagen (Hilden, Germany). RT-PCR Premix kit was obtained from Bioneer (Daejon, Korea). Primers specific for amplifying HMGCS2, NF-kB, and 18s RNA transcripts were purchased from Integrated DNA Technologies (Coralville, IA). Oligonucleotide probes (NF-kB) and the electrophoretic mobility shift assay (EMSA) kit were obtained from Promega Corp (Madison, WI). NF-kB inhibitor, sodium 4aminosalicylate (4-ASA), was purchased from Selleckchem (Houston, TX).

Cell culture and treatment Mouse normal hepatocyte cell line (FL83B) were purchased from ATCC and maintained in F$12 \mathrm{~K}$ medium containing $10 \% \mathrm{FBS}$ and $100 \mathrm{U} / \mathrm{ml}$ penicillin and streptomycin at $37^{\circ} \mathrm{C}$ in $5 \% \mathrm{CO}_{2}$. The cells were placed in airtight chambers (NuAire, Plymouth, MN). At the beginning of each experiment, the cells were re-suspended in F-12K medium at a density of $2.5 \times 10^{5}$ cells $/ \mathrm{ml}$. Cells were treated with D-glucose and silibinin $(40 \mu \mathrm{M})$ for $24 \mathrm{~h}$.

Cell proliferation inhibition Cell viability was assayed by adding 3-(4,5-dimethylthiazol-2-yl)-2,5-diphenyl tetrazolium bromide (MTT) and measuring the blue formazan produced. MTT is metabolized by mitochondrial dehydrogenase, which is active only in live cells. The cells were re-suspended in medium one day before drug treatment, at a density of $3 \times$ $10^{3}$ cells per well in 96 -well culture plates. To determine growth inhibition, cells were incubated with various concentrations of silibinin. For control cells, the medium was replaced with media with DMSO as vehicle control. To measure cell viability, MTT $(5 \mathrm{mg} / \mathrm{ml})$ was added to each well and incubated for $4 \mathrm{~h}$ at $37^{\circ} \mathrm{C}$. The formazan product formed was dissolved by adding $200 \mu \mathrm{l}$ dimethyl sulfoxide (DMSO) to each well, and the absorbance was measured at $550 \mathrm{~nm}$ on an Ultra Multifunctional Microplate Reader (TECAN, Durham, NC). All measurements were performed in triplicate, and experiments were repeated at least three times.

$\beta$-Hydroxybutyrate colorimetric assay Measurements of BHB were performed with a colorimetric assay kit, according to the manufacture's protocol. Briefly, FL83B cells $\left(\sim 18 \times 10^{6}\right)$ 
were collected by centrifugation and sonicated in cold diluted assay buffer. The supernatant was removed, and cells were resuspended in cold diluted assay buffer. BHB standard wells and sample wells were prepared as per the protocol. The reaction was initiated by adding developer solution. Cells were incubated at $25^{\circ} \mathrm{C}$ in the dark for $30 \mathrm{~min}$; then, absorbance was measured at $450 \mathrm{~nm}$.

Western blotting FL83B cell lines were treated with high glucose $(3.78 \mathrm{~g} / \mathrm{l} ; 0.37 \%)$ and silibinin $(40 \mu \mathrm{M})$ for predetermined times. Whole cell cultures were lysed on ice in radio immune precipitation (RIPA) lysis buffer, which contained phosphatase and protease inhibitors. Cells were centrifuged at $15,000 \mathrm{rpm}$ for $10 \mathrm{~min}$ at $4{ }^{\circ} \mathrm{C}$ to remove cellular debris. Protein concentrations were measured with the Bradford method. Western blotting analysis was performed to detect HMGCS2, NF-kB, ANGPTL3, TBP, and $\beta$-actin expression. Equal amounts of proteins were resolved on SDS-PAGE and transferred onto nitrocellulose membranes. The blots were blocked for $1 \mathrm{~h}$ with 5\% skim milk. The membrane was probed overnight at $4{ }^{\circ} \mathrm{C}$ with primary antibodies. Detection with HRP-conjugated secondary antibodies was performed with the WesternBright ECL HRP substrate detection kit and a LAS-4000 imaging device (Fujifilm, Japan).

Reverse transcription polymerase chain reaction FL83B cell lines were treated with high glucose $(3.78 \mathrm{~g} / 1 ; 0.37 \%)$ and silibinin $(40 \mu \mathrm{M})$ for $24 \mathrm{~h}$. Total RNA was extracted with the RNeasy Mini Kit (Qiagen) and quantified spectrophotometrically at $260 \mathrm{~nm}$. We performed reverse-transcription and PCR (RT-PCR) analyses to detect expression of HMGCS2, NF-kB, and 18s RNA. First, cDNA was synthesized from total RNA with a first-strand cDNA synthesis kit (Bioneer, Korea). Reverse transcription was performed at $42^{\circ} \mathrm{C}$ for $1 \mathrm{~h}$ and $80^{\circ} \mathrm{C}$ for $15 \mathrm{~min}$. PCR was conducted with the cDNA. PCR products were analyzed on a $1 \%$ agarose gel stained with ethidium bromide.

Electrophoretic mobility shift assay The DNA-binding activity of NF-kB was detected with an electrophoretic mobility shift assay (EMSA). Briefly, nuclear protein extracts were prepared from treated and untreated cells with the Nuclear Extract Kit (Panomics, Fremont, CA; AY2002). The EMSA experiment was performed by incubating a biotin-labeled transcription factor (TF-NF-kB probe) with the nuclear extracts. Proteins were resolved on a non-denaturing 6\% PAGE gel (Bio-Rad, Korea). The proteins in the gel were transferred to a nylon membrane, and the TF-NF-kB probe was detected with streptavidin-HRP and a chemiluminescent substrate.

NF-kB over-expression analysis FL83B cells $\left(1 \times 10^{5}\right)$ were cultured in 6-well plates and grown to $60 \%$ confluence. The cells were then transfected with wild-NF-kB vector (cFlag
pcDNA3) with the DharmaFECT transfection reagent (Dharmacon, USA) for $24 \mathrm{~h}$. Transfected cells were then treated for an additional $24 \mathrm{~h}$ with low glucose $(1.26 \mathrm{~g} / 1 ; 0.12 \%)$ media that contained $40 \mu \mathrm{M}$ silibinin. Proteins were isolated and analyzed with Western blotting to determine NF-kB and HMGCS2 expression levels.

Statistical analysis All the experiments were repeated three times, and the results were expressed as mean \pm SEM. Groups were compared with the Student's $t$ test. Statistical analyses were performed with the SAS program.

\section{Results}

Silibinin inhibits proliferation of FL83B mouse hepatocytes We used an MTT assay to analyze the inhibitory effects of silibinin on FL83B mouse hepatocyte proliferation (Fig. 1A). We aimed to determine the concentration of silibinin that would produce anti-ketotic activity with little or no effect on cell growth. We analyzed FL83B cell proliferation at increasing concentrations of silibinin. The results showed high percentages of live cells at low concentrations of silibinin, and $40 \mu \mathrm{M}$ silibinin caused little cell death (18\%). Therefore, we used $40 \mu \mathrm{M}$ for further experiments.

Silibinin inhibited in vitro ketosis in FL83B cells We established in vitro ketosis conditions by applying glucose starvation to FL83B cells. We checked BHB expression levels to determine when ketosis was induced. A comparison of BHB expression levels between cells treated with low glucose $(1.26 \mathrm{~g} / 1 ; 0.12 \%)$ and high glucose $(3.78 \mathrm{~g} / 1 ; 0.37 \%)$ showed that glucose starvation successfully induced ketosis (Fig. $1 B$, $C)$. We checked the anti-ketotic effects of silibinin-treating ketotic FL83 cells with $40 \mu \mathrm{M}$ silibinin. The results showed that silibinin reduced BHB levels compared to the levels observed in ketosis. The inhibition of ketone body production suggested that our candidate drug had anti-ketotic properties.

Silibinin inhibited ketosis by regulating HMGCS2 through NFkB signaling HMGCS2 contributes to beta oxidation, which leads to ketone body formation. NF-kB is a transcription factor for HMGCS2. Therefore, an effective anti-ketosis drug should aim to down-regulate the expression levels of both HMGCS2 and NF-kB. In this study, we tested whether $40 \mu \mathrm{M}$ silibinin (the candidate drug) could down-regulate the expression levels of HMGCS2 and NF-kB. We divided cells into three treatment groups: the low glucose $(1.26 \mathrm{~g} / \mathrm{l}$; $0.12 \%)$ group (ketosis group), the high glucose $(3.78 \mathrm{~g} / \mathrm{l}$; $0.37 \%$ ) group (positive control), and the low glucose group treated with $40 \mu \mathrm{M}$ silibinin. We isolated total proteins and total RNA for analysis. RTPCR analyses of total RNA showed that $40 \mu \mathrm{M}$ silibinin down-regulated both HMGCS2 and NF- 


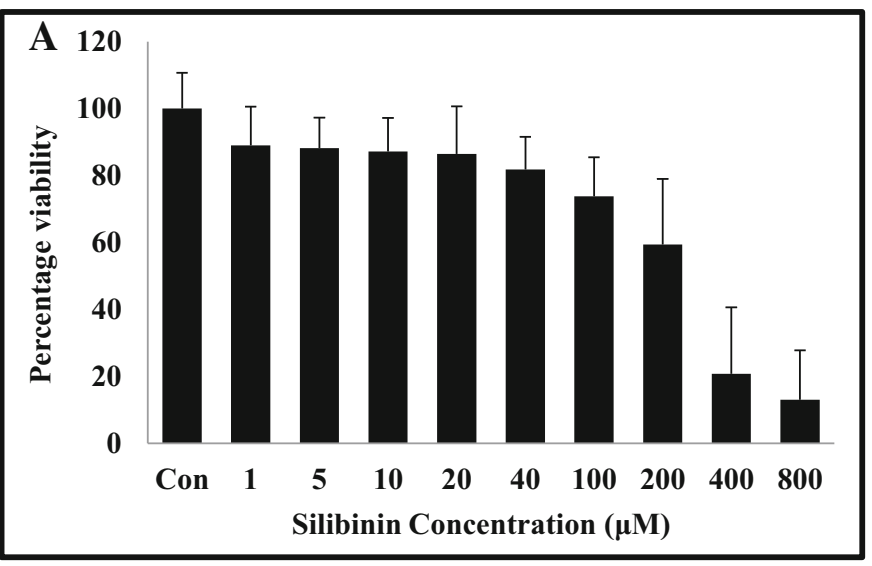

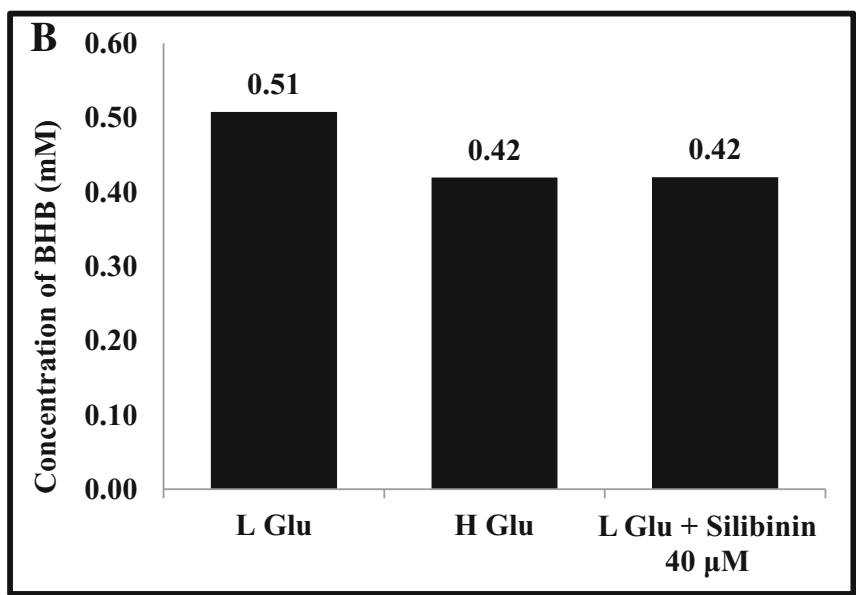

Figure 1. Silibinin inhibited FL83B mouse hepatocyte proliferation and ketosis in vitro. (A) MTT results show that silibinin inhibits FL83B cell proliferation in a dose-dependent manner. The minor effect of $40 \mu \mathrm{M}$ silibinin indicated that it could be used in further analysis. $(B)$ Colorimetric quantification of $\beta$-hydroxybutyrate (BHB) shows the

kB expression (Fig. 2A). Silibinin significantly inhibited HMGCS2 expression (Fig. 2B). Total proteins analyzed on western blots (Fig. $2 C, D$ ) showed the same results; thus, silibinin had anti-ketotic effects at both the RNA and protein levels. Because angiopoietin-like 3 (ANGPTL3) has been considered a molecular target for ketosis treatment, we also tested whether silibinin affected angiopoietin-like 3 (ANGPTL3) expression. We found that silibinin inhibited ANGPTL3 expression, which provided strong support for silibinin as an anti-ketosis agent (Fig. 2C).

Silibinin inhibited the nuclear translocation and DNA binding activity of NF-kB in FL83B mouse hepatocytes Based on our finding that silibinin inhibited NF-kB expression at the transcriptional and translational levels, we reasoned that silibinin might influence NF-kB nuclear translocation, which is required for the transcriptional role of NF-kB in the nucleus. Therefore, we analyzed nuclear extracts isolated from cells grown in low glucose $(1.26 \mathrm{~g} / \mathrm{l} ; 0.12 \%)$, high glucose

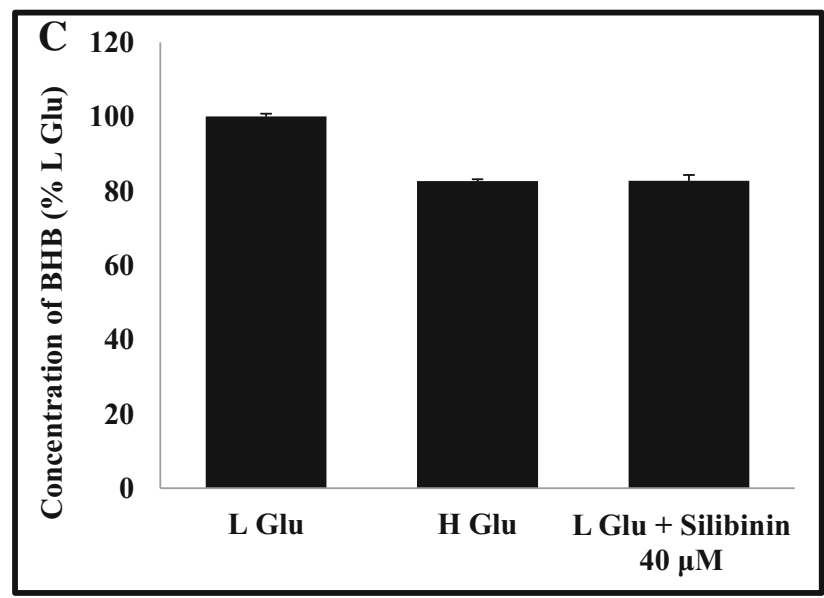

in vitro ketosis in high glucose $(3.78 \mathrm{~g} / \mathrm{l} ; 0.37 \%)$ and in low glucose $(1.26 \mathrm{~g} / \mathrm{l} ; 0.12 \%)$ conditions, with or without $40 \mu \mathrm{M}$ silibinin. $(C)$ Graphical representation of relative BHB levels in FL83B cells treated in media with high glucose and in low glucose, with or without $40 \mu \mathrm{M}$ silibinin. $* * * P<0.001$, based on the Student $t$ test.

(3.78 g/l; 0.37\%), and low glucose with silibinin (Fig. 3A). We found that silibinin significantly inhibited the expression of HMGCS2 and NF-kB in nuclear extracts (Fig. 3B). These results suggested that silibinin inhibited the nuclear translocation of both NF-kB and HMGCS2. Next, we analyzed the DNA binding activity of NF-kB with an electrophoretic mobility shift assay (EMSA). We used a labeled DNA oligonucleotide (gamma interferon activation site), which was known to bind specifically to NF-kB, to examine the DNA binding activity. We found that silibinin down-regulated the formation of the NF-kB/DNA complex (Fig. 3C). These results suggested that NF-kB might be involved in the anti-ketosis effects of silibinin.

NF-kB positively regulated the expression of HMGCS2 in ketosis treatment Silibinin inhibited NF-kB expression and its DNA binding activity. Silibinin also inhibited the expression of HMGCS2 at the RNA and protein levels. These results indicated that HMGCS2 and NF-kB were inhibited upon 
A

\begin{tabular}{|c|c|c|c|c|}
\hline Drug $(\mu \mathrm{M})$ & -- & -- & SB 40 & \\
\hline \multirow[t]{3}{*}{ Glucose } & Low & High & Low & \\
\hline & $=$ & hesens & (2) & HMGCS2 \\
\hline & & & & NF-кB \\
\hline
\end{tabular}

B

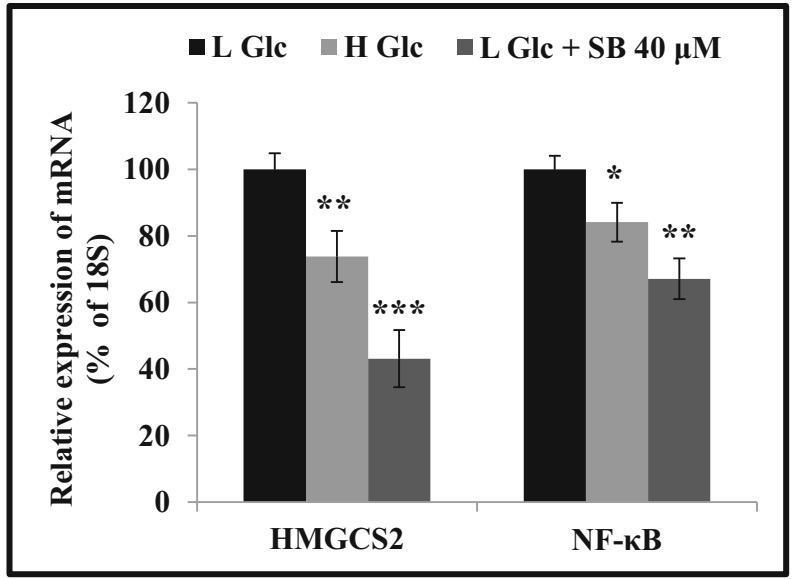

Figure 2. Silibinin inhibited ketosis by regulating HMGCS2 and NF-kB signaling molecules. (A) RT-PCR results show HMGCS2 and NF-kB RNA expression after cells were treated with $40 \mu \mathrm{M}$ silibinin for $24 \mathrm{~h}$. (B) Graphical representation of HMGCS2 and NF-kB inhibition by silibinin at the transcriptional level. $(C)$ Western blot results shows the

silibinin treatment. To determine the exact relationship between NF-kB and HMGCS2, we inhibited NF-kB activity with a specific inhibitor, sodium 4-aminosalicylate (4-ASA). First, we examined the down-regulation of NF-kB expression at different concentrations of 4-ASA with western blotting. We found that $0.5 \mathrm{mM}$ 4-ASA was appropriate for inhibiting NF-kB expression (Fig. 4A). We also found that this NF-kB inhibitor also inhibited the expression of HMGCS2 in whole cell lysates. Next, we performed western blotting to analyze total protein expression with or without 4-ASA (Fig. 4B). In 4ASA-treated cells, silibinin significantly down-regulated the expression of HMGCS2, compared to cells that were not exposed to silibinin (Fig. 4C). Nevertheless, down-regulation of HMGCS2 expression by the NF-kB inhibitor suggested that $\mathrm{NF}-\mathrm{kB}$ acted as a positive regulator for HMGCS2. This relationship was confirmed when we over-expressed NF-kB in FL83B cells by transfecting with a vector that carried the wild-type NF-kB DNA sequence. A western blot analysis of HMGCS2 expression (Fig. 5A) showed an increase in the expression of HMGCS2, in both silibinin-treated and silibinin-treated cells (Fig. 5B). These results showed that
C

$\begin{array}{lrrr}\text { Drug }(\mu M) & -- & -- & \text { SB } 40 \\ \text { Glucose } & \text { Low } & \text { High } & \text { Low }\end{array}$

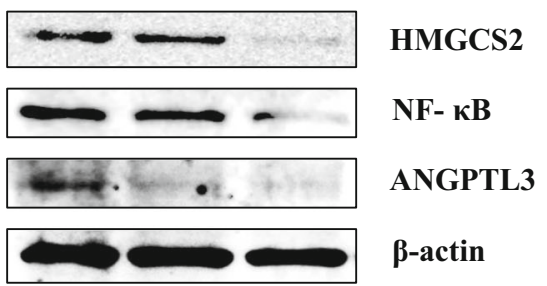

D

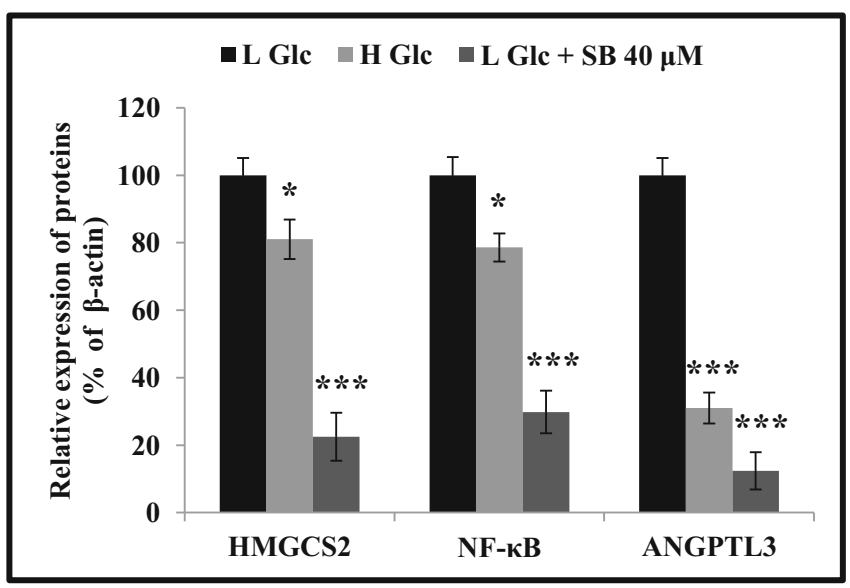

expression patterns of ANGPTL3, HMGCS2, and NF-kB proteins, after cells were treated with $40 \mu \mathrm{M}$ silibinin for $24 \mathrm{~h}$. (D) Relative expression of ANGPTL3, HMGCS2, and NF-kB proteins. $* P<0.05$, $* * P<0.01$, and $* * * \mathrm{P}<0.001$, based on the Student $t$ test.

NF-kB played a vital role in the effect of silibinin on ketosis by acting as a positive regulator of HMGCS2.

\section{Discussion}

The induction of in vitro ketosis with the glucose starvation method can be used to identify anti-ketosis effects of a candidate drug (Sreekantan Preetha et al. 2015). Here, we used the low glucose concentration $(0.12 \%)$ media $(\mathrm{F}-12 \mathrm{~K})$ to induce ketosis, and we increased the glucose concentration thrice for control conditions (high-glucose condition; $3.78 \mathrm{~g} / 1 ; 0.37 \%$ glucose). We showed that the BHB level was significantly reduced in the high glucose group compared to the low glucose $(1.26 \mathrm{~g} / 1 ; 0.12 \%)$ group (Fig. $2 B$ ). Silibinin is a flavonoid that has been used as a hepatoprotector for several years (Hogan et al. 2007). It is typically given orally to treat hepatic diseases (Cheung et al. 2010). Silibinin is very active in liver, and ketosis is produced in the liver; therefore, we tested silibinin activity against ketosis in FL83B mouse hepatocytes. Our results 
A

$\begin{array}{lrrr}\text { Drug }(\mu \mathrm{M}) & -- & -- & \text { SB } 40 \\ \text { Glucose } & \text { Low } & \text { High } & \text { Low }\end{array}$

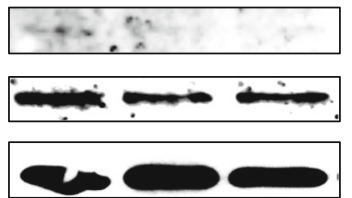

HMGCS2

NF- $\kappa B$

TBP

B

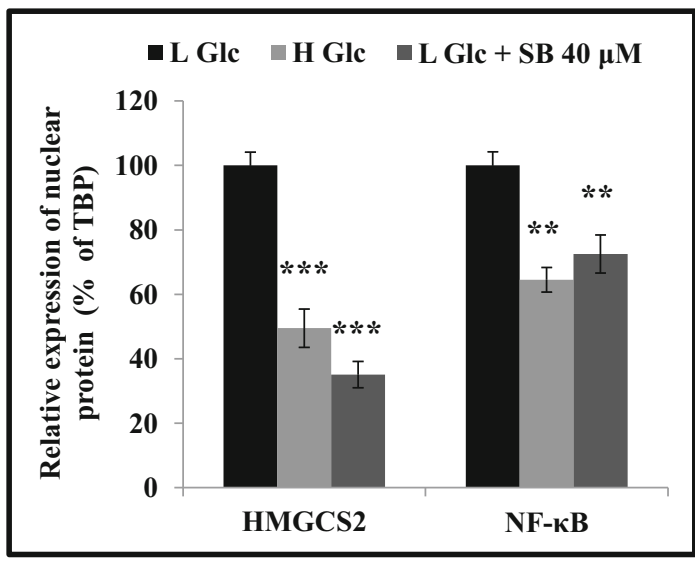

Figure 3. Silibinin enhanced the nuclear translocation and DNA-binding activity of NF-kB in FL83B cells. (A) Western blot analysis of nuclear extract proteins from cells exposed to low glucose (1.26 g/l; 0.12\%), high glucose $(3.78 \mathrm{~g} / \mathrm{l} ; 0.37 \%)$, or low glucose plus $40 \mu \mathrm{M}$ silibinin for $24 \mathrm{~h}$. $(B)$ Relative expression patterns of HMGCS2 and NF-kB nuclear

showed that silibinin reduced the BHB levels in the group of cells treated with low glucose. At the same time, the concentration of silibinin is considered an important factor in anti-ketosis treatments. An anti-ketosis drug should be designed to cause little or no effect on cell growth. We found that a concentration of $40 \mu \mathrm{M}$ silibinin inhibited $18 \%$ of cell proliferation, after a treatment period of $24 \mathrm{~h}$. Our BHB analysis showed that $40 \mu \mathrm{M}$ silibinin could inhibit ketosis in vitro.

HMGCS2 and ANGPTL3 promote ketosis through different pathways. During beta oxidation, HMGCS2 plays an important role in the conversion of acetyl-CoA and acetoacetylCoA to HMG-CoA, which is then converted to acetoacetic acid and BHB (Vilà-Brau et al. 2011). In contrast, ANGPTL3 is involved in carbohydrate and fat metabolism disorders; thus, it is considered a molecular target for ketosis treatments (Xiao et al. 2012). Inhibition of these molecules leads to the inhibition of ketosis. Silibinin inhibited both these target molecules at the transcriptional level, and it also inhibited HMGCS2 at the translational level, in FL83B cells. These results indicated that silibinin had anti-ketotic properties. In addition, silibinin blocked the nuclear translocation of HMGCS2. Taken together, these findings showed that silibinin inhibited ketosis by blocking the expression and activity of HMGCS2 during beta oxidation.
C

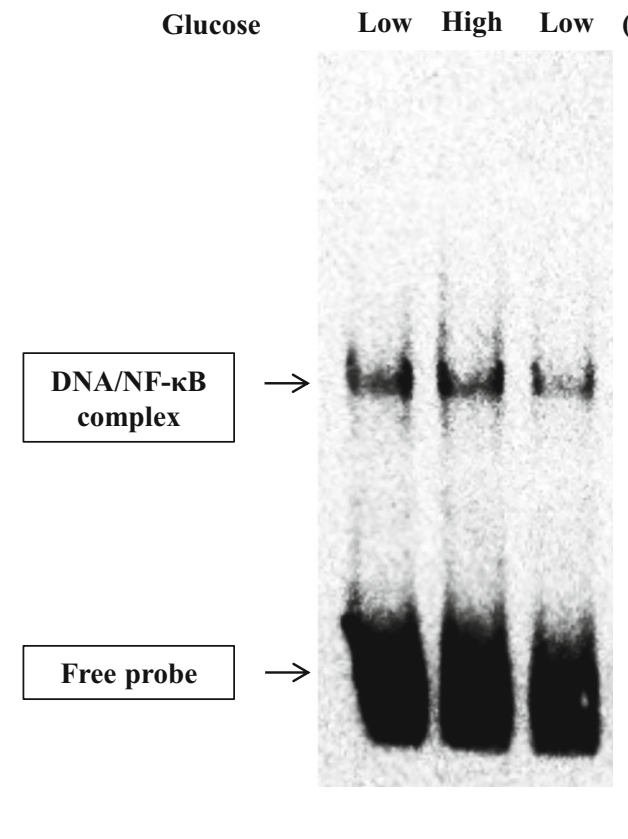

proteins. (C) Gel shift analysis of nuclear extracts shows NF-kB binding to the gamma interferon activation site element in DNA from cells treated with low glucose, high glucose, or low glucose plus $40 \mu \mathrm{M}$ silibinin. Images are representative of three independent experiments. $* * P<0.01$ and $* * * P<0.001$, based on the Student $t$ test.

$\mathrm{NF}-\mathrm{kB}$ is a transcription factor that regulates the HMGCS2 gene. The NF-kB signaling pathway participates in the production of CCL and CXCL (Nookala et al. 2013), and CXCL chemokines are inhibited by PPAR $\alpha$ activators (Antonelli et al. 2010). HMGCS2 interacts with PPAR $\alpha$ to co-activate PPRE sites in DNA to increase gene transcription (Kostiuk et al. 2010). Thus, NF-kB plays a role in the activity of HMGCS2 through various signaling molecules. However, it was unknown whether NF-kB played role in the expression of HMGCS2 during ketosis treatment. Recent studies showed that NF-kB played a vital role in osteoclastogenesis in bone marrow-derived macrophages (Joung et al. 2016). A previous study showed that elevated BHB concentrations activated the NF-kB signaling pathway, and thereby induced hepatocyte inflammatory disorder (Shi et al. 2014), which suggested that NF$\mathrm{kB}$ might play a role in ketosis. We investigated the role of NF$\mathrm{kB}$ in ketotic FL83B cells. Our candidate drug, silibinin, reduced $\mathrm{NF}-\mathrm{kB}$ expression at the transcriptional level and the translational level. Additionally, $40 \mu \mathrm{M}$ silibinin suppressed the nuclear translocation and the DNA binding activity of NF-kB. These results showed that ketosis treatment down-regulated NF-kB expression, which suggested that NF-kB played a role in ketosis.

We found that HMGCS2 and NF-kB played vital roles in ketosis. Thus, these molecules might be considered molecular targets for treating ketosis. Although NF-kB is a transcription 
A

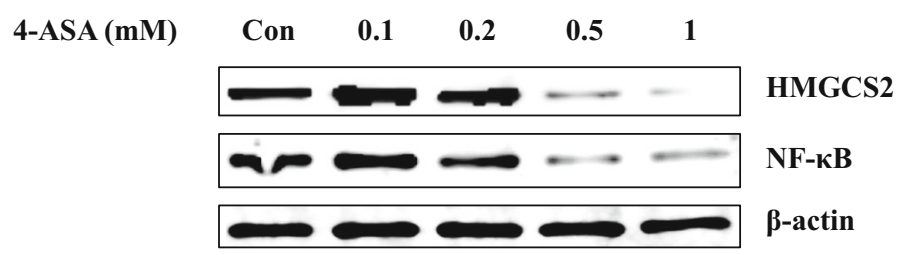

B

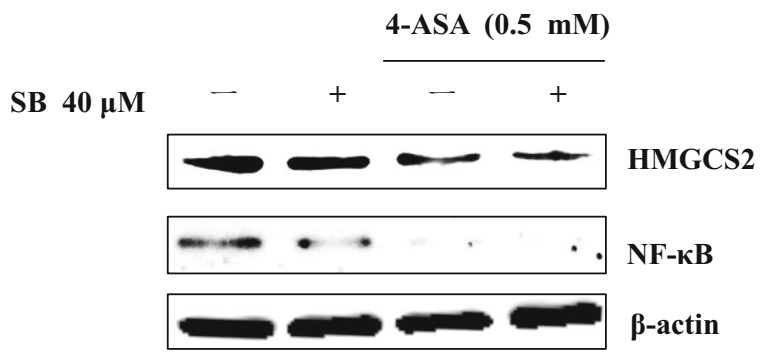

C

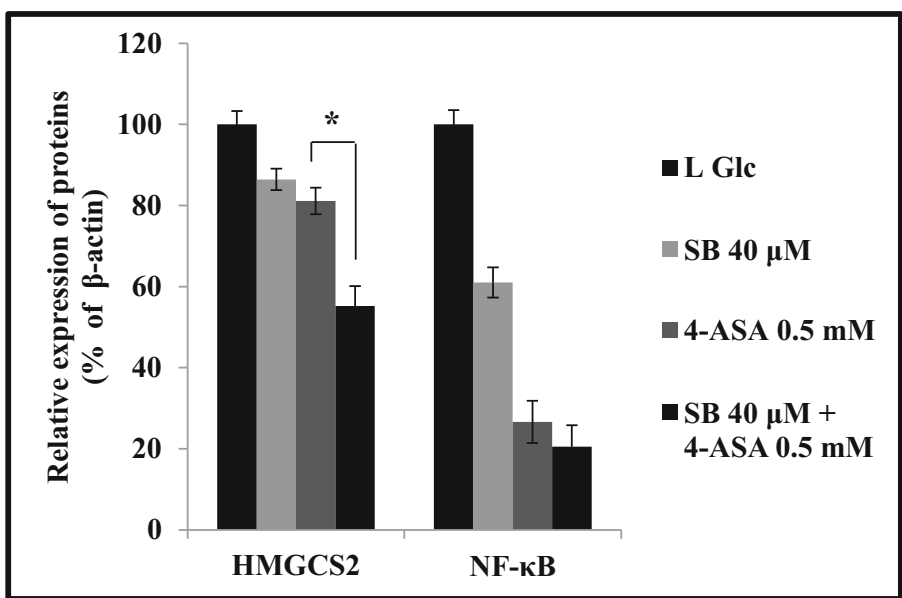

Figure 4. Role of NF-kB in the expression of HMGCS2 under ketotic conditions. (A) Western blot analysis of HMGCS2 and NF-kB in cells treated with different concentrations of the NF-kB inhibitor, 4-ASA. $(B)$ Western blot analysis shows the results of NF-kB inhibition with 4-ASA,

and the levels of HMGCS2 and NF-kB in cells treated with silibinin for $24 \mathrm{~h}$. (C) Graphical representation of the relative expression of NF-kB and HMGCS2 with respect to $\beta$-actin. $* P<0.05$, based on the Student $t$ test.

factor for HMGCS2, it remained unknown whether this regulation was positive or negative. Our results showed that silibinin treatment down-regulated the expression of both molecules. Therefore, we hypothesized that NF-kB acted as a positive regulator of HMGCS2. To confirm this, we inhibited NF-kB with its specific inhibitor and then checked the expression of HMGCS2. The result showed that HMGCS2 expression was also down-regulated in NF-kB inhibitor-treated cells.

B

A

\section{NF-кB}

\section{over expression}

SB $40 \mu M$

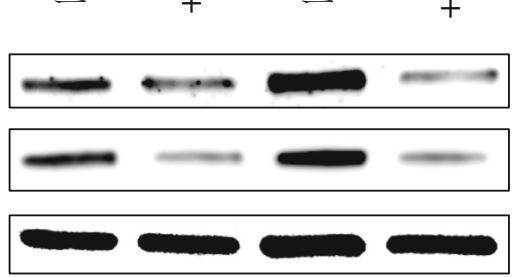

HMGCS2

NF-кB

$\beta$-actin

Figure 5. NF-kB effects on the expression of HMGCS2 during antiketosis treatment. (A) Western blot analysis shows the expression of HMGCS2 and NF-kB after cells that over-expressed NF-kB were treated

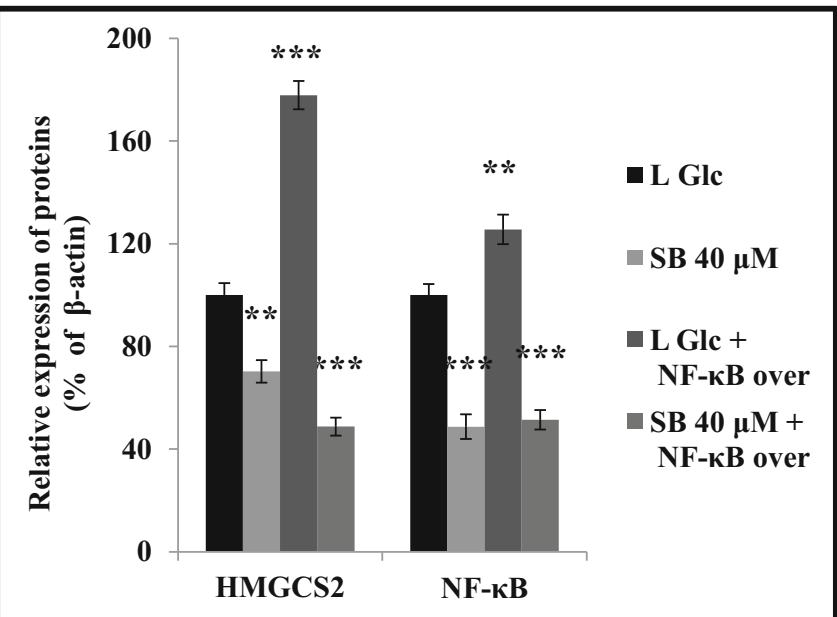

with silibinin for $24 \mathrm{~h}$. $(B)$ Relative expression levels of NF-kB and HMGCS2 compared to $\beta$-actin. $* * P<0.01$ and $* * * P<0.001$, based on the Student $t$ test. 
Conversely, NF-kB over-expression up-regulated HMGCS2 expression. These results provided solid evidence that NF-kB acted as a positive regulator of HMGCS2.

\section{Conclusion}

In conclusion, this study showed that silibinin inhibited in vitro ketosis by inhibiting an HMGCS2-targeted NF-kB signaling pathway and by inhibiting the DNA binding activity of NF-kB. Our study also showed that NF-kB acted as a positive regulator of HMGCS2 during ketotic conditions. Altogether, silibinin can be considered as a candidate drug for anti-ketosis research and the added advantage of silibinin as a drug is it has less side effects and more efficacy.

Funding Information This work was supported by a grant from the Next Generation BioGreen 21 Program (No. PJ01110901, PJ01315101), Rural Development Administration, Republic of Korea.

Open Access This article is distributed under the terms of the Creative Commons Attribution 4.0 International License (http:// creativecommons.org/licenses/by/4.0/), which permits unrestricted use, distribution, and reproduction in any medium, provided you give appropriate credit to the original author(s) and the source, provide a link to the Creative Commons license, and indicate if changes were made.

\section{References}

Abrahan C, Ash JD (2016) The potential use of PGC- $1 \alpha$ and PGC- $1 \beta$ to protect the retina by stimulating mitochondrial repair. Adv Exp Med Biol 854:403-409

Antonelli A, Ferrari SM, Frascerra S, Pupilli C, Mancusi C, Metelli MR, Orlando C, Ferrannini E, Fallahi P (2010) CXCL9 and CXCL11 chemokines modulation by peroxisome proliferator-activated receptor-alpha agonists secretion in Graves' and normal thyrocytes. J Clin Endocrinol Metab 95:E413-E420

Cheung CW, Gibbons N, Johnson DW, Nicol DL (2010) Silibinin-a promising new treatment for cancer. Anti Cancer Agents Med Chem 10:186-195

Cotter DG, Ercal B, Huang X, Leid JM, d'Avignon DA, Graham MJ, Dietzen DJ, Brunt EM, Patti GJ, Crawford PA (2014) Ketogenesis prevents diet-induced fatty liver injury and hyperglycemia. J Clin Invest 124:5175-5190

Davis-Searles PR, Nakanishi Y, Kim NC, Graf TN, Oberlies NH, Wani MC, Wall ME, Agarwal R, Kroll DJ (2005) Milk thistle and prostate cancer: differential effects of pure flavonolignans from Silybum marianum on antiproliferative end points in human prostate carcinoma cells. Cancer Res 65:4448-4457

Duyao MP, Buckler AJ, Sonenshein GE (1990) Interaction of an NFkappa B-like factor with a site upstream of the c-myc promoter. Proc Natl Acad Sci U S A 87:4727-4731

Garber AJ, Menzel PH, Boden G, Owen OE (1974) Hepatic ketogenesis and gluconeogenesis in humans. J Clin Invest 54:981-989

Hegardt FG (1999) Mitochondrial 3-hydroxy-3-methylglutaryl-CoA synthase: a control enzyme in ketogenesis. Biochem J 338:569-582

Hogan FS, Krishnegowda NK, Mikhailova M, Kahlenberg MS (2007) Flavonoid, silibinin, inhibits proliferation and promotes cell-cycle arrest of human colon cancer. J Surg Res 143:58-65
Iademarco MF, McQuillan JJ, Rosen GD, Dean DC (1992) Characterization of the promoter for vascular cell adhesion molecule-1 (VCAM-1). J Biol Chem 267:16323-16329

Joung YH, Darvin P, Kang DY, Sp N, Byun HJ, Lee CH, Lee HK, Yang YM (2016) Methylsulfonylmethane inhibits RANKL-induced osteoclastogenesis in BMMs by suppressing NF- $\mathrm{KB}$ and STAT3 activities. PLoS One 11:e0159891

Kostiuk MA, Keller BO, Berthiaume LG (2010) Palmitoylation of ketogenic enzyme HMGCS2 enhances its interaction with PPARalpha and transcription at the Hmgcs2 PPRE. FASEB J 24:1914-1924

Kumar S, Raina K, Agarwal C, Agarwal R (2014) Silibinin strongly inhibits the growth kinetics of colon cancer stem cell-enriched spheroids by modulating interleukin 4/6-mediated survival signals. Oncotarget 5:4972-4989

Lawrence T (2009) The nuclear factor NF-kappaB pathway in inflammation. Cold Spring Harb Perspect Biol 1:a001651

Mateen S, Tyagi A, Agarwal C, Singh RP, Agarwal R (2010) Silibinin inhibits human nonsmall cell lung cancer cell growth through cellcycle arrest by modulating expression and function of key cell-cycle regulators. Mol Carcinog 49:247-258

Nookala AR, Shah A, Noel RJ, Kumar A (2013) HIV-1 tat-mediated induction of CCL 5 in astrocytes involves NF- $\mathrm{BB}, \mathrm{AP}-1, \mathrm{C} / \mathrm{EBP} \alpha$ and $\mathrm{C} / \mathrm{EBP} \gamma$ transcription factors and JAK, PI3K/Akt and $\mathrm{p} 38$ MAPK signaling pathways. PLoS One 8:e78855

Saller R, Brignoli R, Melzer J, Meier R (2008) An updated systematic review with meta-analysis for the clinical evidence of silymarin. Forsch Komplementmed 15:9-20

Shi X, Li X, Li D, Li Y, Song Y, Deng Q, Wang J, Zhang Y, Ding H, Yin L, Zhang Y, Wang Z, Li X, Liu G (2014) $\beta$-Hydroxybutyrate activates the NF- $\mathrm{KB}$ signaling pathway to promote the expression of pro-inflammatory factors in calf hepatocytes. Cell Physiol Biochem 33:920-932

Singh RP, Agarwal R (2005) Mechanisms and preclinical efficacy of silibinin in preventing skin cancer. Eur J Cancer 41:1969-1979

Sreekantan Preetha N, Kang DY, Darvin P, Kim DN, Joung YH, Kim SY, Cho KH, Do CH, Park KD, Lee JH, Lee HY, Park JH, Yang YM (2015) Induction of in vitro ketosis condition and suppression using methylsulfonylmethane by altering ANGPTL3 expression through STAT5b signaling mechanism. Anim Cells Syst 19:30-38

Tensen CP, Flier J, Rampersad SS, Sampat-Sardjoepersad S, Scheper RJ, Boorsma DM, Willemze R (1999) Genomic organization, sequence and transcriptional regulation of the human CXCL 11(1) gene. BiochimBiophysActa 1446:167-172

Ueda A, Okuda K, Ohno S, Shirai A, Igarashi T, Matsunaga K, Fukushima J, Kawamoto S, Ishigatsubo Y, Okubo T (1994) NFkappa B and Sp1 regulate transcription of the human monocyte chemoattractant protein-1 gene. J Immunol 153:2052-2063

Vilà-Brau A, De Sousa-Coelho AL, Mayordomo C, Haro D, Marrero PF (2011) Human HMGCS2 regulates mitochondrial fatty acid oxidation and FGF21 expression in HepG2 cell line. J Biol Chem 286: 20423-20430

Wang HJ, Wei XF, Jiang YY, Huang H, Yang Y, Fan SM, Zang LH, Tashiro S, Onodera S, Ikejima T (2010) Silibinin induces protective superoxide generation in human breast cancer MCF-7 cells. Free Radic Res 44:90-100

Xiao HB, Sun ZL, Zhou N (2012) 1,3,5,8-Tetrahydroxyxanthone regulates ANGPTL3-LPL pathway to lessen the ketosis in mice. Eur J Pharm Sci 46:26-31

Zeng J, Sun Y, Wu K, Li L, Zhang G, Yang Z, Wang Z, Zhang D, Xue Y, Chen Y, Zhu G, Wang X, He D (2011) Chemopreventive and chemotherapeutic effects of intravesicalsilibinin against bladder cancer by acting on mitochondria. Mol Cancer Ther 10:104-116 